九州大学学術情報リポジトリ

Kyushu University Institutional Repository

\title{
Physical Properties of Water Treatment Residue and Their Effects on Plant Growth as a Substitute Soil
}

\section{Park, Seok-Gon}

Institute of Tropical Agriculture, Graduate School of Social and Cultural Studies, Kyushu University

Yahata, Hisashi

Emeritus Professor of Kyushu University

Saeki, Kazutoshi

Biotron Institute, Graduate School of Bioresource and Bioenvironmental Sciences, Kyushu University

Kurosawa, Kiyoshi

Institute of Tropical Agriculture, Kyushu University

他

https://doi.org/10.5109/16135

出版情報: 九州大学大学院農学研究院紀要. 54 (2)，pp.481-487，2009-10-29. Faculty of Agriculture, Kyushu University

バージョン :

権利関係 : 


\title{
Physical Properties of Water Treatment Residue and Their Effects on Plant Growth as a Substitute Soil
}

\author{
Seok-Gon PARK ${ }^{1 *}$, Hisashi YAHATA ${ }^{2}$, Kazutoshi SAEKI ${ }^{3}$, \\ Kiyoshi KUROSAWA and Young-Jin KIM
}

\author{
Institute of Tropical Agriculture, Kyushu University, Hakozaki, 6-10-1, Fukuoka 812-8581, Japan \\ (Received June 29, 2009 and accepted July 13, 2009)
}

\begin{abstract}
Technology that can reuse a larger amount of water treatment residue (WTR) is required. In this study, the physical properties of the WTR, and the WTR medium to which organic materials (OM) were added, were measured, and the effects of the properties on plant growth were studied to reuse the medium as a substitute soil. Relative gas diffusivity $\left(\mathrm{D} / \mathrm{D}_{0}\right)$, saturated hydraulic conductivity $\left(\mathrm{K}_{\mathrm{s}}\right)$ and water retention ability of the fine WTR (particle size $<3 \mathrm{~mm}$ ), the coarse WTR (particle size 3-8 mm) and WTR media all displayed high ability for reuse. However, available water capacities (RAW, PAW) of the WTR and WTR media were lower than those of typical soil. The RAW and PAW of the fine WTR were higher than the coarse WTR because capillary porosity of the fine WTR which was composed of relatively small particles retained more water. The RAW and PAW of the fine media were significantly higher than those of coarse media. The plant growth with the fine medium was greater than the coarse medium in the WTR medium with an OM content of $10 \%$. The RAW and PAW may affect plant growth as a limiting factor more than the $\mathrm{D} / \mathrm{D}_{0}, \mathrm{~K}_{\mathrm{s}}$ and water retention ability in the WTR medium with less available water capacity. When making a WTR medium for the substitute soil, a particle size of less than $3 \mathrm{~mm}$ of WTR is recommended.
\end{abstract}

\section{INTRODUCTION}

In Japan, 36,000 tons of water treatment residue (WTR) are produced every year (Horikawa et al., 2007), and it is estimated on a global scale that a massive 10,000 tons of WTR are produced daily (Dharmappa et al., 1997). Vast costs are required to dispose of WTR (Babatunde and Zhao, 2007). Technology that can reuse a larger amount of WTR would be beneficial to the environment. Examples which reused WTR as a substitute were reported: clay substitute materials of cement and brick (Pan et al., 2004; Ramadan et al., 2008), subbase material of geotechnical works (Furukawa et al., 2006), and adsorbent for pollutants (Oh et al., 2009). Currently, applications of WTR to make alterations to the soil are being discussed as an alternative landfill option and for recycling (Heil and Barbarick, 1989; Moodley et al., 2004; Moodley and Hughes, 2006).

On the other hand, undesirable circumstances, such as adsorption of large amounts of plant available phosphorus also were reported (e.g., Bugbee and Frink, 1985; Elliott and Singer, 1988; Ahmed et al., 1997). Several studies supported that WTR improved soil quality of tillage considerably, and that water retention capacity and soil pH resulted in an improvement in crop growth (e.g., Rengasamy et al., 1980; Elliot and Dempsey, 1991; Kim et al., 2002; Moodley and Hughes, 2006).

Physical and chemical properties of WTR depended

\footnotetext{
Institute of Tropical Agriculture, Graduate School of Social and Cultural Studies, Kyushu University, 819-0395, Fukuoka, Japan

2 Emeritus Professor of Kyushu University, 812-8581, Fukuoka, Japan

3 Biotron Institute, Graduate school of Bioresource and Bioenvironmental Sciences, Kyushu University

* Corresponding author (E-mail: park@agr.kyushu-u.ac.jp)
}

greatly upon characteristics of the raw water source, coagulant types, applied dosage of coagulants, and dewatering process (Babatunde and Zhao, 2007). Typically, coagulants of polyaluminum chloride (PAC) and aluminum sulfate were added during the water treatment process in Japan. Minerals and humic substances were combined and precipitated from raw water. The suspended solid flocs were concentrated in the dewatering process, and then as WTR. When the flocs were dehydrated, the WTR was a platy aggregate with a thickness of 3-10 mm with homogeneous water content (Yoshida, 2005). The coagulant used in the water treatment process irreversibly binds to silt and clay particles (Zhang and Miller, 1996). By airdrying, the WTR had a gravel texture (Moodley et al., 2004; Moodley and Hughes, 2006). Therefore, the pulverization process of WTR is necessary to generate an appropriate particle size. A soil substitute should have suitable physical properties (e.g., water retention, aeration, and structure) for plant growth.

On the other hand, Elliot and Dempsey (1991) showed that WTR generally had little fertilizer value. The addition of fertilizer and organic matter such as: biosolids, compost and wood fiber was necessary to improve the nutrients in WTR, so that WTR was reused as plant based soil and soil amendment material (Elliott and Dempsey, 1991; Ippolito et al., 1999).

Our purposes in this study are the followings 1) to compare physical properties between particle size distribution for $<3 \mathrm{~mm}$ (fine WTR) and 3-8 mm (coarse WTR), and between fine and coarse WTR media. These WTR media contained organic matter such as, compost and wood fiber and, 2) to clarify the effect of particle size distribution on plant growth to examine the possibility of reusing WTR as a substitute soil. 


\section{MATERIAL AND METHODS}

\section{Materials}

WTR was collected from the Tatara water purification plant in Fukuoka City, Japan. The WTR of around $1 \mathrm{~m}^{3}$ was collected in November 2007 from the water purification plant to assess physical properties and plant growth. The WTR was produced after the flocculation process with aggregates by adding PAC (polyaluminium chloride) and the dewatering process occurred under pressure in the water purification plant. The collected WTRs were angular aggregates $12-35 \mathrm{~mm}$ in diameter with a $4 \mathrm{~mm}$ thickness, the water content of which was $121 \%$ (w $\mathrm{w}^{-1}$ ) on average.

Labor and time were necessary for pulverization and sieving in order to generate appropriate particle size because water content of the WTR was high. Therefore, the WTR was ground with a crusher, and was distributed at sizes of less than $3 \mathrm{~mm}$ (fine WTR) and $3-8 \mathrm{~mm}$ (coarse WTR) by a sieve for making WTR medium for practical purpose. Decomposed granite soil (DGS) was taken from a vegetationless area of Mt. Tachibana in Fukuoka Prefecture. The DGS was sieved into particles that were less than $3 \mathrm{~mm}$ in diameter for use as a control soil.

The particle size distribution of original WTR and DGS determined by dry sieving and the hydrometer method (Gelndon and Dani, 1996) showed that fine WTR, coarse WTR and DGS belonged to the coarsest textural classes, loamy sand, gravel and sandy loam, respectively (US Department of Agriculture scheme). The fine WTR consisted mostly of sand (78.0\%) with a low percentage of clay (2.4\%), while DGS consisted of gravel (47.2\%) and sand (45.7\%) (Park et al., 2009a).

The original WTR was added with organic materials (OM), i.e. wood fiber and compost to improve the content of nutrients. The WTR added with OM was expected to be able to use as a growth medium for plants (Park et al., 2009b). For fine and coarse WTR, the ratio of OM was controlled in two classes, 10 and $20 \%$ of the total volume of the dried materials. The compost content was fixed at $10 \%$ of the total, but the wood fiber content was changed from $0 \%$ to $10 \%$ (WTR+OM10, WTR+OM20). The DGS when only control was added remained at 10\% (DGS+ OM10).

\section{Physical properties of materials}

In order to measure physical properties of the fine WTR, coarse WTR and WTR media, air-dried portions of each sample were repacked by hand with equal pressure into stainless steel cylinders $(5.1 \mathrm{~cm}$ tall, $5.0 \mathrm{~cm}$ i.d.). The samples were then saturated overnight. The water retention curves of the samples were determined to be $-1,-4,-6,-13,-40,-100,-600$ and $-1500 \mathrm{~J} \mathrm{~kg}^{-1}$ by the water desorption method (Filnt and Filnt, 2002). Water desorption of the samples was controlled by measuring with the hanging water column method at a high matric potential of $-1,-4,-6$ and $-13 \mathrm{~J} \mathrm{~kg}^{-1}$ (Dane and Hopmans, 2002a). Measurements of the lower matric potential at -40 and $-100 \mathrm{~J} \mathrm{~kg}^{-1}$ were done by the pressure plate method (Dane and Hopmans, 2002b). Furthermore, at the lowest matric potential of -600 and $-1500 \mathrm{~J} \mathrm{~kg}^{-1}$, the samples were controlled by a centrifuge method (Reatto et al., 2008). Gas diffusivity (D) was also measured at $-1,-4$, $-6,-13,-40$ and $-100 \mathrm{~J} \mathrm{~kg}^{-1}$ matric potential using a hanging water column and pressure plate methods. Then, relative gas diffusivity $\left(\mathrm{D} / \mathrm{D}_{0}\right)$ of the samples was determined by the methods of Rolston and Moldrup (2002) and Osozawa (1987). The samples were re-saturated overnight in order to measure saturated hydraulic conductivity $\left(\mathrm{K}_{\mathrm{s}}\right)$ using the falling head method (Reynolds et al., 2002).

Readily available water (RAW) and plant available water (PAW) of samples were calculated from the difference of the water retained between the matric potentials of $-6 \mathrm{~J} \mathrm{~kg}^{-1}$ and $-100 \mathrm{~J} \mathrm{~kg}^{-1}$, and $-6 \mathrm{~J} \mathrm{~kg}^{-1}$ and $-1500 \mathrm{~J} \mathrm{~kg}^{-1}$, respectively (Moodley et al., 2004). Total porosity was calculated from the measurement of bulk density and particle density using the pycnometer method (Flint and Flint, 2002). Capillary porosity (capillary water) was defined as the amount of pores that retain water at a $-4 \mathrm{~J}$ $\mathrm{kg}^{-1}$ matric potential (Bigelow et al., 2004). Macro porosity (air-filled) was calculated by subtracting the water content at $-4 \mathrm{~J} \mathrm{~kg}^{-1}$ from total porosity.

Each sample has three replications chosen by a completely random experimental design for all measurements. The physical properties of the fine WTR, fine WTR medium and DGS were cited from Park et al. (2009a).

\section{Plant growth experiment}

The plant growth experiment was performed with the fine WTR medium and coarse WTR medium. Camphor tree (Cinnamonum camphora) seedlings were planted to determine the performance of the WTR media on seedling growth. Treatment plots of WTR+OM10, WTR+OM20 and DGS+OM10 (control) were randomly assigned in each block following the randomized complete block design. The experimental area consisted of three blocks; each consisted of three treatment plots (Fig. 1). The particle size treatment of WTR (fine and coarse WTR) was set up as a subplot within the treatment plots of WTR+ OM10 and WTR+OM20.

The WTR media were filled into nonwoven fabric pots that were $48 \mathrm{~cm}$ in diameter at the top and $27 \mathrm{~cm}$ high.

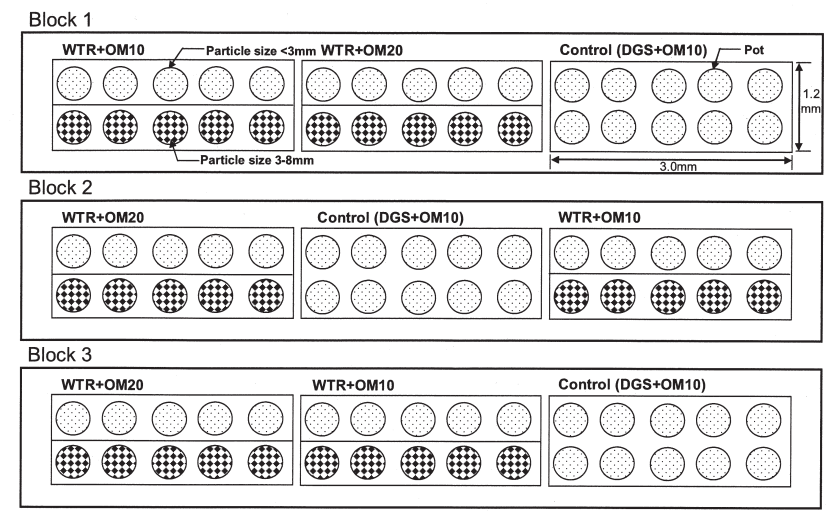

Fig. 1. Randomized complete block design of the plant growth experiment. 
The pots were buried in the ground to a depth of $25 \mathrm{~cm}$ to avoid direct sunlight. The seedlings with relatively the same height and diameter were selected from the containerized seedings, and the mean tree height, root-collar diameter and crown area were $0.15 \pm 0.03 \mathrm{~m}, 3 \pm 0.6 \mathrm{~mm}$ and $0.009 \pm 0.004 \mathrm{~m}^{2}$, respectively. There were no significant differences in the tree height, root-collar diameter or crown area of the seeding among treatments. The size of each treatment plot was $1.2 \mathrm{~m} \times 3.0 \mathrm{~m}$. Here, 10 seedlings of Camphor tree were planted with a $0.6 \mathrm{~m} \times 0.6 \mathrm{~m}$ spacing between the seedlings, for a total of 30 seedlings in each block.

The seedlings were also fertilized with $32 \mathrm{~g}$ of slowrelease fertilizers (IBDU; Wood Ace 4, Mitsubishi Chemical Agri, Inc., Japan), meaning that each seedling received $3840 \mathrm{mg}$ of nitrogen (N), $845 \mathrm{mg}$ of phosphorus (P), 1594 mg of potassium $(\mathrm{K})$ and $384 \mathrm{mg}$ of magnesium $(\mathrm{Mg})$ in total. The seedlings were irrigated one at a time by hand during a period of one week in the dry season from May to June. The transplanted seedlings were grown in a field in Tachibanakuti, Fukuoka Prefecture in south-western Japan for 7 months from May 2008 to November 2008. The tree height, root-collar diameter and crown area of all the seedlings were measured in November 2008.

Mean statistical differences among treatment types were determined by the analysis of variance using SPSS software (Version 11, 2002). Significance was assigned by Tukey multiple comparison test using rank-ordered means. For the data of water content and $\mathrm{D} / \mathrm{D}_{0}$, Bonferroni corrections were used for comparing means when interactions were statically significant among the fine WTR and coarse WTR. Unless otherwise noted, a value of $p<0.05$ was considered to indicate a significant difference.

\section{RESULTS}

\section{Comparison in physical properties between fine and coarse WTRs}

The fine WTR saturated at a higher level of water content, $0.563 \mathrm{~m}^{3} \mathrm{~m}^{-3}$ on average, than the coarse WTR $(p<0.001)$, at a matric potential of $-1 \mathrm{~J} \mathrm{~kg}^{-1}$. The water content of the fine WTR decreased rapidly to $0.345 \mathrm{~m}^{3} \mathrm{~m}^{-3}$ until the matric potential decreased to $-13 \mathrm{~J} \mathrm{~kg}^{-1}$ (Fig. 2). Afterwards, the fine WTR released water slowly (Park et al., 2009a). However, the water content of the coarse WTR was significantly lower than the fine WTR with a matric potential from -1 to $-1500 \mathrm{~J} \mathrm{~kg}^{-1}$. The water content of the coarse WTR decreased rapidly to $0.315 \mathrm{~m}^{3} \mathrm{~m}^{-3}$ at a matric potential of $-1 \mathrm{~J} \mathrm{~kg}^{-1}$, and its coarse WTR was 1.6 times lower than that of fine WTR. Afterwards, the coarse WTR released water slightly with the decrease in matric potential. The control (original DGS) released water more slowly throughout the changes in matric potential from -1 to $-1500 \mathrm{~J} \mathrm{~kg}^{-1}$. The control lost most of the water $\left(0.090 \mathrm{~m}^{3} \mathrm{~m}^{-3}\right)$ at $-1500 \mathrm{~J} \mathrm{~kg}^{-1}$; whereas, both WTR retained 2.5 times the amount of water $\left(0.228 \mathrm{~m}^{3} \mathrm{~m}^{-3}\right)$.

$\mathrm{D} / \mathrm{D}_{0}$ of the coarse WTR was significantly higher than that of fine WTR in the matric potential from -1 to $-1500 \mathrm{~J}$ $\mathrm{kg}^{-1}$ (Fig. 3). When the matric potential was $-1 \mathrm{~J} \mathrm{~kg}^{-1}, \mathrm{D} /$ $\mathrm{D}_{0}$ of the fine WTR was 0.015 . D/ $\mathrm{D}_{0}$ rose from 0.015 to
0.075 with a matric potential from $-6 \mathrm{~J} \mathrm{~kg}^{-1}$ to $-13 \mathrm{~J} \mathrm{~kg}^{-1}$. Afterwards, D/D 0 of the fine WTR rose slightly. However, $\mathrm{D} / \mathrm{D}_{0}$ of the coarse WTR was 27 times higher than the fine WTR at a matric potential of $-1 \mathrm{~J} \mathrm{~kg}^{-1}$, and $\mathrm{D} / \mathrm{D}_{0}$ rose slightly with a decreasing matric potential. $\mathrm{D} / \mathrm{D}_{0}$ of the control increased with the decrease of the matric potential, but the pattern was different between the control and the fine WTR. When the matric potential was more than $-4 \mathrm{~J} \mathrm{~kg}^{-1}, \mathrm{D} / \mathrm{D}_{0}$ of the control and the fine WTR were not significantly different. After this, $\mathrm{D} / \mathrm{D}_{0}$ of the fine WTR increased rapidly to 0.036 with the decrease in matric potential until $-6 \mathrm{~J} \mathrm{~kg}^{-1}$ was significantly higher than the control (Park et al., 2009a).

Total porosity and macro porosity of coarse WTR were significantly higher than those for fine WTR. However,

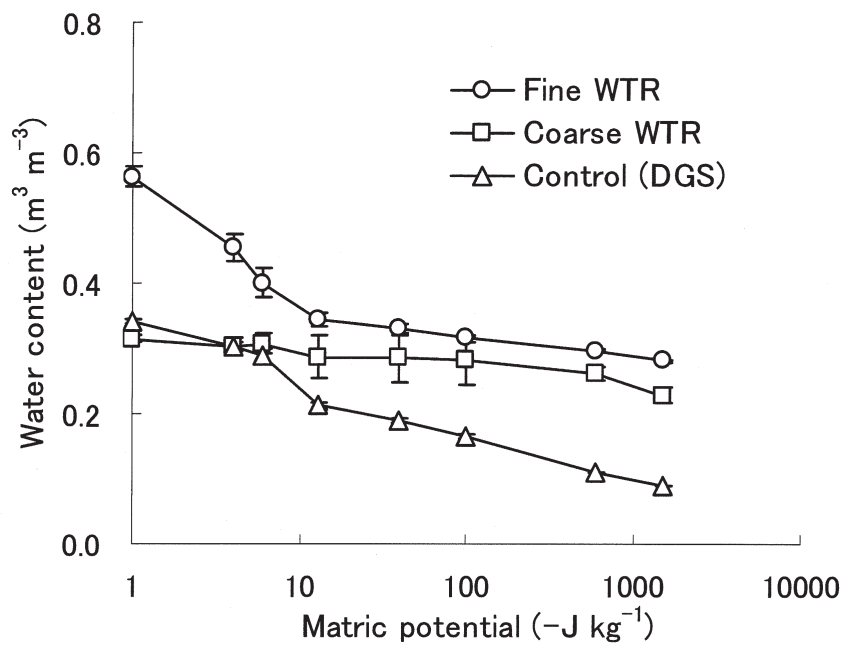

Fig. 2. Water retention characteristics of fine water treatment residue (WTR) and coarse WTR. The error bars indicate standard deviations $(n=3)$.

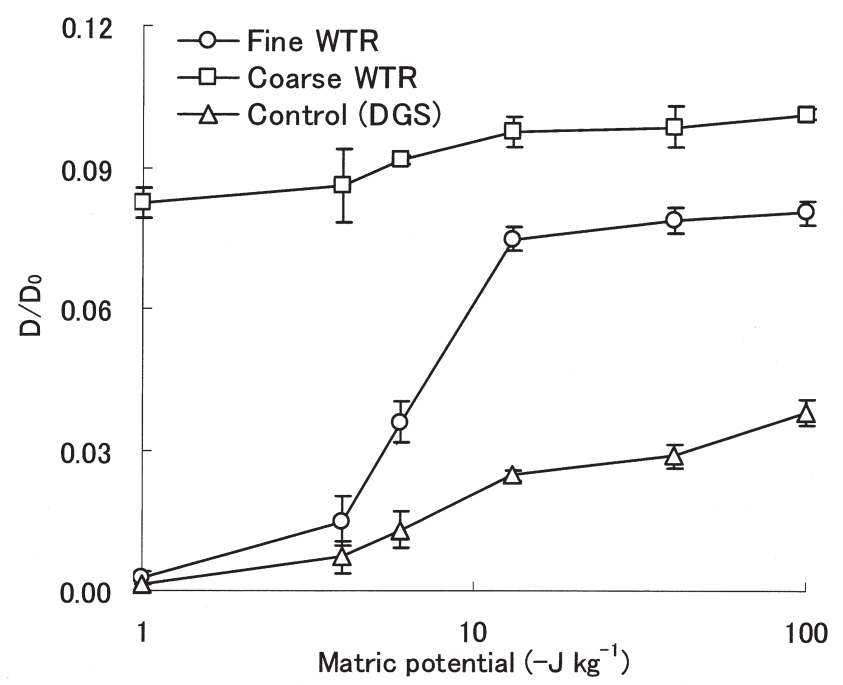

Fig. 3. Changes in soil gas diffusivities $\left(D / D_{0}\right)$ of fine water treatment residue (WTR) and coarse WTR according to the variation of matric potential. The error bars indicate standard deviations $(n=3)$. 
capillary porosity of the fine WTR was significantly higher than that for coarse WTR (Table 1). Because total porosity and macro porosity of the coarse WTR were high, the $\mathrm{K}_{\mathrm{s}}$ of the coarse WTR was approximately 20 times higher than that of fine WTR.

When OM is added to the WTR, $\mathrm{K}_{\mathrm{s}}$ is increased due to the increase in total porosity, but it decreased RAW and PAW. In the fine WTR medium with an OM content of $10 \%$ had the significantly lower value of total porosity than in other WTR media, and macro porosity of the fine WTR media were significantly lower than that of coarse WTR media. However, its capillary porosity tended to be higher than in other WTR media (Table 1). Because the porosity of the coarse media was high, the $\mathrm{K}_{\mathrm{s}}$ was significantly higher than that of fine WTR media. RAW and PAW of the fine media were significantly higher than those of coarse media. PAW of the fine medium with an OM content of $10 \%$ was significantly higher than in the WTR media.

\section{Plant growth}

Significant differences of Camphor tree growth were observed between the fine and coarse media in the plant growth experiment (Fig. 4). In the medium with an OM content of $10 \%$, tree height, root-collar diameter and crown area of the fine medium were significantly higher than for the coarse medium. However, no significant differences were observed in the medium with an OM content of $20 \%$. Tree height and crown area of the fine medium were significantly higher than the control. Tree height in the coarse medium with an OM content of $10 \%$ was significantly higher than the control.

\section{DISCUSSION}

\section{Effect of particle size distribution on physical properties of the WTRs}

The water retention characteristic was closely related to pore size distribution, particle packing, shape, and orientation (Campbell, 1985). Pore structure of coarse particles released water through gravitational drainage at a high matric potential (Bigelow et al., 2004). In this study, water in the coarse WTR was almost lost through gravitational drainage at a high matric potential. The fine WTR retained a lot more water than the coarse WTR at a high matric potential because the fine WTR that composed of relatively small particles may retain water in capillary porosity. The aggregates of the WTR made internal pores to trap air during the flocculation process (Moodley and Hughes, 2006). Because the internal pores in aggregates of WTR retained water, the water content of WTR was higher than the control (original DGS) at a low matric potential (Park et al., 2009a). This suggests that the water retention ability of WTR may be quite high.

The rate of soil gas diffusion depends on air porosity, tortuosity and air continuity (Currie, 1961). Relative gas diffusivity $\left(\mathrm{D} / \mathrm{D}_{0}\right)$ linearly increased with the increase of air-filled porosity (Osozawa, 1987; Campbell, 1985). In the study, $\mathrm{D} / \mathrm{D}_{0}$ of the fine, the coarse WTR and control increased with the increase of air-filled porosity, but the patterns were different between treatments. Because the porous WTR released water from the pores between the particle unit, and the pores became a passage for gas diffusion, the $\mathrm{D} / \mathrm{D}_{0}$ of the fine and coarse WTR were higher than that of control at a high matric potential. The D/ $\mathrm{D}_{0}$ and water retention of WTR were higher than the control because water was retained within internal pores of WTR (Park et al., 2009a). The growth of the plant root was limited when $\mathrm{D} / \mathrm{D}_{0}$ was less than 0.02 (Grable and Siemer, 1967; Gliński and Stepniewski, 1985). D/D $\mathrm{D}_{0}$ of the fine and coarse WTR was more than 0.02 at the matric potential of $-6 \mathrm{~J} \mathrm{~kg}^{-1}$. This implied that plant growth was not limited by gas diffusion in the WTR media.

PAW and RAW of the fine WTR were higher than the coarse WTR. These results indicated that capillary porosity of the fine WTR, which was composed relatively of small particles, retained water, and the water retention characteristic of the WTR changed with particle size distribution. PAW of the fine WTR $\left(0.119 \mathrm{~m}^{3} \mathrm{~m}^{-3}\right)$ was lower

Table 1. Available water capacities (RAW, PAW), saturated hydraulic conductivity $\left(\mathrm{K}_{\mathrm{s}}\right)$, porosity of fine water treatment residue (WTR), coarse WTR and WTR media $(n=3)$

\begin{tabular}{|c|c|c|c|c|c|c|c|}
\hline \multirow[t]{2}{*}{ Material } & \multicolumn{3}{|c|}{ Porosity } & \multicolumn{2}{|c|}{$\begin{array}{c}\text { Available water } \\
\text { capacities }\left(\mathrm{m}^{3} \mathrm{~m}^{-3}\right)\end{array}$} & \multirow{2}{*}{$\begin{array}{c}\mathrm{K}_{\mathrm{s}}{ }^{2)} \\
\left(\mathrm{m} \mathrm{s}^{-1}\right)\end{array}$} & \multirow{2}{*}{$\begin{array}{c}\text { Bulk } \\
\text { density } \\
\left(\mathrm{Mg} \mathrm{m}^{-3}\right)\end{array}$} \\
\hline & Total & Macro & Capillary & RAW ${ }^{1)}$ & PAW ${ }^{1)}$ & & \\
\hline Fine WTR (original) & $0.660 \mathrm{~d}$ & $0.205 \mathrm{~d}$ & $0.455 \mathrm{a}$ & $0.085 \mathrm{a}$ & $0.119 \mathrm{~b}$ & $5.12 \times 10^{-4} \mathrm{c}$ & 0.77 \\
\hline Fine WTR+OM10 & $0.677 \mathrm{c}$ & $0.313 c$ & $0.364 \mathrm{~b}$ & $0.062 \mathrm{bc}$ & $0.107 \mathrm{~b}$ & $3.68 \times 10^{-3} \mathrm{c}$ & 0.74 \\
\hline Fine WTR+OM20 & $0.689 \mathrm{~b}$ & $0.339 \mathrm{bc}$ & $0.351 \mathrm{bc}$ & $0.051 \mathrm{c}$ & $0.084 \mathrm{c}$ & $7.40 \times 10^{-3} \mathrm{~b}$ & 0.67 \\
\hline Coarse WTR (original) & $0.698 \mathrm{ab}$ & $0.309 \mathrm{c}$ & $0.389 \mathrm{~b}$ & $0.027 \mathrm{~d}$ & $0.080 \mathrm{~cd}$ & $9.98 \times 10^{-3} \mathrm{~b}$ & 0.72 \\
\hline Coarse WTR+OM10 & $0.696 a b$ & $0.379 \mathrm{a}$ & $0.317 \mathrm{dc}$ & $0.019 \mathrm{~d}$ & $0.047 \mathrm{e}$ & $1.62 \times 10^{-2} \mathrm{a}$ & 0.69 \\
\hline Coarse WTR+OM20 & $0.701 \mathrm{a}$ & $0.375 \mathrm{ab}$ & $0.325 \mathrm{bcd}$ & $0.024 \mathrm{~d}$ & $0.063 \mathrm{de}$ & $1.70 \times 10^{-2} \mathrm{a}$ & 0.68 \\
\hline Control (DGS) +OM10 & $0.486 \mathrm{e}$ & $0.189 \mathrm{~d}$ & $0.297 \mathrm{~d}$ & $0.072 \mathrm{ab}$ & $0.161 \mathrm{a}$ & $1.10 \times 10^{-4} \mathrm{c}$ & 1.36 \\
\hline
\end{tabular}

1) RAW: Readily available water (between matric potential of $-6 \mathrm{~J} \mathrm{~kg}^{-1}$ and $-100 \mathrm{~J} \mathrm{~kg}^{-1}$ ); PAW: Plant available water (between matric potential of $-6 \mathrm{~J} \mathrm{~kg}^{-1}$ and $-1500 \mathrm{~J} \mathrm{~kg}^{-1}$ ).

${ }^{2)} \mathrm{K}_{\mathrm{s}}$ : Saturated hydraulic conductivity. Means followed by the same letter are not significantly different according to Tukey multiple comparison test. 
than that of typical soil in which PAW was $0.300 \mathrm{~m}^{3} \mathrm{~m}^{-3}$ as a maximum (Dayton and Basta, 2001). The water retention ability of WTRs is known to be high, but the available water capacity of WTRs is generally low (Elliot and Dempsey, 1991; Ahmed et al., 1997). Moodley et al. (2004), Moodley and Hughes (2006) reported that an application of WTR with rates between 0 and $1280 \mathrm{Mg} \mathrm{ha}^{-1}$ and an incorporation depth of $0.20 \mathrm{~m}$ had the effect of

(a) Tree height

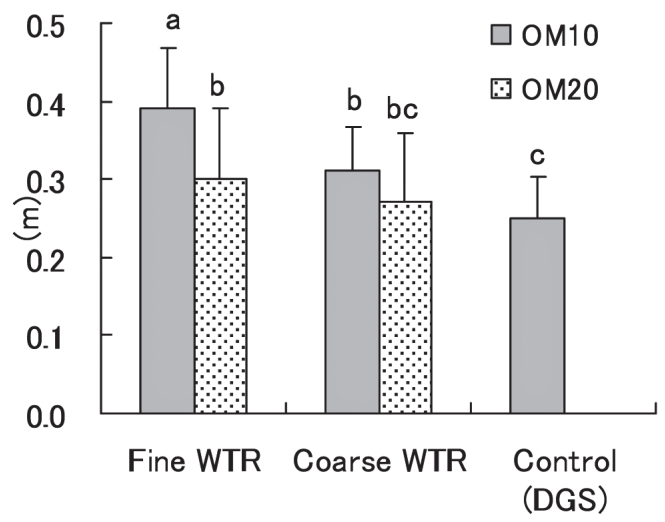

(b) Root-collar diameter

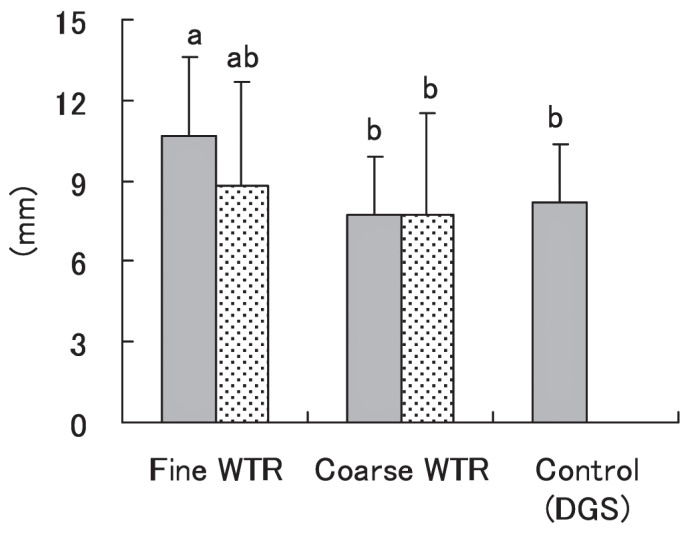

(c) Crown area

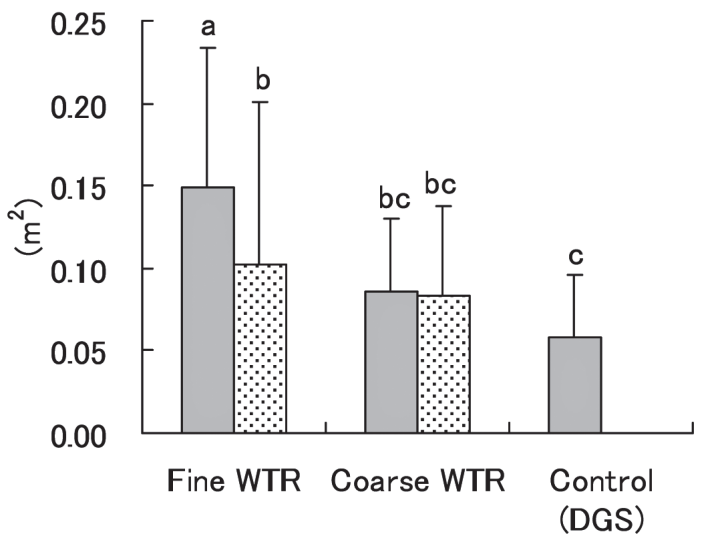

Fig. 4. Growths of the Camphor tree in the water treatment residual (WTR) media. The error bars indicate standard deviations. Means followed by the same letter are not significantly different according to Tukey multiple comparison test.
WTR application on South African soils showing that the water retention of the soils must increase. However, the RAW and PAW were not significantly different between the treatments. In the study, because the available water of the fine WTR which was composed relatively of small particles increased, this result suggested that the available water capacity of WTR may increase by producing the appropriate particle size distribution and the pore structure of WTR. It is expected that the increase of the available water capacity is effective for the growth of plants.

A gravel or sandy soil with large pores can have a higher $\mathrm{K}_{\mathrm{s}}$ than clay soil (Hillel, 1998). Clogging in pores by clay migration can alter $\mathrm{K}_{\mathrm{s}}$ markedly as shown in the saturated flow experiments (Campbell, 1985). Aggregates of WTR have high stability and limited potential for swelling in the case of water absorption due to the tenacity with which the polymer that was added during the water treatment process binds the silt and clay (Moodley and Hughes, 2006). Aggregated soil particles are less susceptible to detachment and erosion (Elliot and Dempsey, 1991). When water flowed through pores of the WTR, a change in the passage and blockage of water flow by small soil particles did not occur. The $\mathrm{K}_{\mathrm{s}}$ of WTR was higher than that of control. Because the total porosity and the macro porosity of the coarse WTR largely were high, its $\mathrm{K}_{\mathrm{s}}$ may be higher than the fine WTR.

Because $D / \mathrm{D}_{0}, \mathrm{~K}_{\mathrm{s}}$ and water retention ability of the original WTR were high, the improvement benefit of physical properties by the addition of OM was small, and rather it was the opposite effect in the case of RAW and PAW. The available water is an important property of soil relating to crop production in a growth medium (Jiang et al., 2007). When available water capacity is small, it may become a limiting factor in plant growth.

\section{Effect of physical properties on plant growth}

According to the results of the growth experiment, the plant growth of the fine medium, where RAW and PAW were high, was higher than that of the coarse medium in the media with an OM content of $10 \%$.

It seems that the RAW and PAW were affected by plant growth as a limiting factor more so than the $\mathrm{D} / \mathrm{D}_{0}$ and $K_{s}$ in the WTR medium with a small available water capacity. A similar result was obtained in the growth medium of sawdust and shavings (Allaire et al., 2005). Allaire et al. (2005) reported that in the growth media of high hydraulic conductivity and gas diffusion, the growth limiting factor was available water. The WTR medium was able to be superior to the control (DGS) based on physical properties such as: $\mathrm{D} / \mathrm{D}_{0}, \mathrm{~K}_{\mathrm{s}}$, water retention ability and chemical properties such as: EC, Total-N, CEC (Park et al., 2009b). Therefore, it appears that the plant growth in fine WTR medium was higher than the control (DGS).

\section{CONCLUSIONS}

$\mathrm{D} / \mathrm{D}_{0}, \mathrm{~K}_{\mathrm{s}}$, water retention ability of the fine and coarse WTR were all shown to be high. However, RAW and PAW of the fine WTR, the coarse WTR and WTR media were 
lower than those of typical soil. The RAW and PAW of the fine WTR were higher than the coarse WTR. In the WTR media, the RAW and PAW of the fine media were higher than those of coarse media. The RAW and PAW of WTR may increase by producing the appropriate particle size and pore structure.

The plant growth of the fine medium was higher than the coarse medium in the WTR media with an OM content of $10 \%$. The RAW and PAW may affect plant growth as a limiting factor more so than the $\mathrm{D} / \mathrm{D}_{0}, \mathrm{~K}_{\mathrm{s}}$ and water retention ability in the WTR medium. In order to reuse WTR for a substitute soil for planting, the particle size of less than $3 \mathrm{~mm}$ of WTR may be preferable.

\section{REFERENCES}

Ahmed, M., Grant, C. D., Oades, J. M., and Tarrant, P. 1997 Water treatment sludge: potential for use as a soil ameliorant. Urban Water Res. Assoc. of Australia, Research report No. 106, pp. 51

Allaire, S. E., Caron, J., Ménard, C., Dorais, M. 2005 Potential replacements for rockwool as growing substrate for greenhouse tomato. Can. J. Soil Sci., 85: 67-74

Babatunde, A. O., and Zhao, Y. Q. 2007 Constructive approaches toward water treatment works ludge management: An international review of beneficial reuses. Crit. Rev. Environ. Sci. Tech., 37: 129-164

Bigelow, C. A.; Bowman, D. C.; and Casseld, D. K. 2004 Physical properties of three sand size classes amended with inorganic materials or sphagnum peat moss for putting green rootzones. Crop. Sci., 44(3): 900-907

Campbell, G. S. 1985 Soil physics with basic: transport models for soil-plant systems. Elsevier. New York, pp. 150

Currie, J. A. 1961 Gaseous diffusion in porous media. Part 3-Wet granular materials. Br. J. Appl. Physics, 12: 275-281

Dane, J. H., and Hopmans, J. W. 2002b Pressure plate extractor. In "Methods of soil analysis. Part 4: Physical methods", ed. by J. H. Dane and G. C. Topp, SSSA Book Ser. No. 5. SSSA, Madison, Wisconsin (USA), pp. 688-690

Dane, J. H., and Hopmans., J. W. 2002a Hanging water column. In "Methods of soil analysis. Part 4: Physical methods", ed. by J. H. Dane and G. C. Topp, SSSA Book Ser. No. 5. SSSA, Madison, Wisconsin (USA), pp. 680-688

Dayton, E. A., and Basta, N. T. 2001 Characterization of drinking water treatment residuals for use as a soil substitute. Water Environ. Res., 73(1): 52-57

Dharmappa, H. B., Hasia, A., and Hagare, P. 1997 Water treatment plant residuals management. Water Sci. Technol., 35(8): $45-56$

Elliott, H. A., and Dempsey, B. A. 1991 Agronomic effects of land application of water treatment sludge, J. Am. Water Works Assoc., 83(4): 126-131

Elliott, H. A., and Singer, L. M. 1988 Effect of water treatment sludge on growth and elemental composition of tomato (Lycopersicon esculentum) shoots. Commun. Soil Sci. Plant Anal., 19: 345-354

Flint, L. E., and Flint, A. L. 2002 Porosity. In "Methods of soil analysis. Part 4: Physical methods", ed. by J. H. Dane and G. C. Topp, SSSA Book Ser. No. 5. SSSA, Madison, Wisconsin (USA), pp.241-254

Furukawa, Y., Aizu, D., and Fujita, T. 2006 A study on the application of clean-water sludge as a geomaterial. J. Japan Soc. Civil Engin., 813: 203-214 (in Japanese with English summary)

Gelndon, W. G., and Dani O., D. 2002 Particle-size analysis. In "Methods of soil analysis. Part 4: Physical methods" ed. by J. H. Dane and G. C. Topp, SSSA Book Ser. No. 5. SSSA, Madison, Wisconsin (USA), pp. 255-293

Gliński J., and Stepniewski W. 1985 Soil Aeration and Its Role for
Plants. CRC Press, Boca Raton, Florida (USA) pp. 107-165

Grable, A. R., and Siemer, E. G. 1968 Effects of bulk density, aggregate size and soil-water suction on oxygen diffusion, redox potentials and on elongation of corn roots. Soil Sci. Soc. Am. J., 32: 180-186

Heil, D. M., and Barbarick, K. A. 1989 Water treatment sludge influence on the growth of sorghum-sudangrass. J. Environ. Qual., 18: 292-298

Hillel, D. 1998 Environmental soil physics. Academic Press, San Diego (USA), pp. 173-201

Horikawa, T., Ito, T., Hasegawa, T., Masuda, Y., Arai, T., Saigusa, M. 2007 Properties of polysilicate-iron (PSI) sludge from water purification plants: Its effects on rice growth and methane emission. J. sci. soil and manure, 78(3): 261-267 (in Japanese with English summary)

Ippolito, J. A., Barbarick, K. A., and Redente, E. F. 1999 Coapplication effects of water treatment residuals and biosolids on two range grasses. J Environ Qual., 28: 1644-1650

Jiang, P, Anderson, S. H., Kitchen, N. R., Sudduth, K. A., and Sadler, E. J. 2003 Estimating plant-available water capacity for claypan landscapes using apparent electrical conductivity. Soil Sci Soc Am J., 71: 1902-1908

Kim, J. G., Lee, S. S., Moon, H. S., and Kang I. M., 2002 Land application of alum sludge from water purification plant to acid mineral soil treated with acidic water. Soil Sci. Plant Nutr. 48(1): 15-22

Moodley, M., Johnston, M. A., Hughes, J. C., and Titshall, L. W. 2004 Effects of a water treatment residue, lime, gypsum and polyacrylamide on the water retention and hydraulic conductivity of two contrasting soils under field conditions in KwaZuluNatal, South Africa. Aust. J. Soil Res., 42: 273-282

Moodley, M., and Hughes J. C. 2006 The effects of a polyacrylamide-derived water treatment residue on the hydraulic conductivity, water retention and evaporation of four contrasting South African soils and implications for land disposal. Water Sci Technol., 54(5): 227-3324

Oh, T. K., Chikushi, J. and Saeki, K. 2009 The adsorption of hydrogen fluoride and fluoride ion on a water treatment sludge. $J$. Fac. Agr., Kyushu Univ., 54(1): 205-209

Osozawa, S. 1987 Measurement of soil-gas diffusion coefficient for soil diagnosis. Soil Phys. Condit. Plant Growth., 55: 53-60 (in Japanese with English summary)

Pan, J. R., Huang, C., and Lin, S. 2004 Reuse of fresh water sludge in cement making. Water Sci. Technol., 50(9): 183-188

Park, S. G., Ohashi, M. Kurosawa, K., Yahata, H and Kim, Y. J. 2009a Physical properties of water treatment residue and possibility to reuse it as an alternative soil material (unpublished manuscript submitted for publication)

Park, S. G., Ohashi, M. and Yahata, H. 2009b Plants growth on water treatment residual for reuse water treatment residue substitute soil (unpublished manuscript)

Ramadan, M. O., Fouad, H. A. and Hassanain, A. M. 2008 Reuse of water treatment plant sludge in brick manufacturing. J. Appl. Sci. Res., 4(10): 1223-1229

Reatto, A., Medrado da Silva, E., Bruand, A., Souza Martins, E., and Werneck, J. E. F. 2008 Lima validity of the centrifuge method for determining the water retention properties of tropical soils. Soil Sci. Soc. Am. J., 72: 1547-1553

Rengasamy, P., J. M. Oades, and T. W. Hancock. 1980 Improvement of soil structure and plant growth by addition of alum sludge. Commun. Soil Sci. Plant Anal., 11: 533-545

Reynolds, W. D., Elrick, D. E., Youngs, E. G., Amoozegar, A., Booltink, H. W. G., and Bouma, J. 2002 Saturated and field-saturated water flow parnmeters. In "Methods of soil analysis. Part 4: Physical methods", ed. by J. H. Dane and G. C. Topp, SSSA Book Ser. No. 5. SSSA, Madison, Wisconsin (USA), pp. 797-878

Rolston, D. E., and Moldrup, P. 2002 Gas Diffusivity In "Methods of Soil Analysis. Part 4: Physical methods", ed. by J. H. Dane and G. C. Topp, SSSA Book Ser. No. 5. SSSA, Madison, Wisconsin (USA), pp. 1113-1139

Yoshida, s. 2005 (Water treatment work sludge reuse from water purification plant: application of water treatment sludge as soil 
amendment). Agriculture and horticulture, 80(3): 368-376 (in Japanese)*

Zhang, X. C. and Miller, W. P. 1996 Polyacrylamide effects on infiltration and erosion in furrows. Soil Sci.Soc. Am. J., 60: $866-872$
* The title parentheses are tentatively translated from the original Japanese titles by authors. 